\title{
Generation of Free Radicals in Lipid Emulsion Used in Parenteral Nutrition
}

\author{
OLLI PITKÄNEN, MIKKO HALLMAN, AND STURE ANDERSSON
}

Children's Hospital, Stenbäckinkatu 11, 00290, Helsinki, Finland 1O.P., M.H., S.A.]; University of California Irvine, Orange, California /M.H.J; and Department of Medical Chemistry, Siltavuorenpenger 10, 00170,

Helsinki, Finland [S.A.]

\begin{abstract}
Lipid emulsions used in parenteral nutrition are prone to peroxidation that may be an important feature of oxygen-associated tissue damage. Incubation of lipid emulsion [Intralipid (IL)] with $\mathrm{H}_{2} \mathrm{O}_{2}$ and $\mathrm{FeCl}_{2}$ increased lipid peroxidation, measurable as increased production of pentane, from $0.39 \pm 0.33$ to $0.99 \pm 0.18 \mu \mathrm{M}(p<0.0001)$. Malondialdehyde was increased from $0.010 \pm 0.005 \mathrm{mM}$ to $0.380 \pm 0.025 \mathrm{mM}(p<0.001)$. Superoxide dismutase and catalase (each $100 \mathrm{U} / \mathrm{mL})$ or vitamin $C(10 \mathrm{mM})$ inhibited pentane and malondialdehyde production $(p<$ 0.0001 ). Incubation of human erythrocytes in the presence of $\mathrm{FeCl}_{2}$ caused $11.0 \pm 3.2 \%$ hemolysis (control $0.95 \pm$ $0.14 \%$ ). Addition of $0.44 \%$ IL increased hemolysis to 66.5 $\pm 3.4 \%$, whereas further addition of vitamin $E$ or $C$ significantly inhibited hemolysis to $16.4 \pm 8.1$ and $38.9 \pm 7.1 \%$, respectively $(p<0.0001)$. IL was administered i.v. to eight preterm infants. It increased 3 - to 28 -fold $(p<0.001)$ the amount of pentane in expired breath. Partly, this increase was due to pentane dissolved in IL as a result of lipid peroxidation during storage. After discontinuing IL infusion, the elimination of pentane was nonexponential, consisting of a rapid and a slow component. According to our results, IL undergoes peroxidation causing free-radicaldependent damage to human cells. We propose that the adverse effects of parenteral IL are partially caused by free oxygen radicals generated by lipid peroxidation. (Pediatr Res 29: 56-59, 1991)
\end{abstract}

Abbreviations

CAT, catalase

IL, Intralipid

MDA, malondialdehyde

SOD, superoxide dismutase

Premature infants frequently require parenteral nutrition during the first weeks of life. Despite unquestionable nutritional advantages, the infusion of lipids has been associated with decreased oxygenation and accumulation of lipids in pulmonary vessels (1-6). In addition, the use of i.v. lipids in small, premature infants has been related to increased chronic morbidity such as bronchopulmonary dysplasia and retinopathy of prematurity (7)

Several lines of evidence suggest that partially reduced, highly reactive oxygen species, free oxygen radicals, are important in oxidant injury (8). The significance of free-radical-mediated

Received April 20, 1990; accepted August 22, 1990.

Correspondence: Dr. Olli Pitkänen, Children's Hospital, Stenbäckinkatu 11, 00290, Helsinki, Finland.

Supported by the AGA Research Fund, Research and Science Foundation of Farmos, the Foundation for Pediatric Research, the Finnish Academy, and Finska Läkaresällskapet. damage for the outcome of small premature infants has previously been proposed (9). The vulnerability of premature infants may be caused by their inability to resist free oxygen radicals, or by incidents capable of liberating excess free oxygen radicals, such as hyperoxia, respiratory burst by activated phagocytic cells, and episodes of hypoxia-reperfusion (9-12). Lipid peroxidation, free-radical-induced autocatalytic breakdown of polyunsaturated fatty acids, involves a cascade of reactions further liberating reactive intermediates, lipid peroxides $(13,14)$. Therefore, the infusion of a lipid emulsion rich in polyunsaturated fatty acids may cause lipid peroxidation and, consecutively, tissue injury.

This investigation was undertaken to study whether lipid emulsion used in parenteral nutrition undergoes lipid peroxidation in vitro, whether this peroxidation can generate free radicals that damage human cells, and whether generation of free radicals can be demonstrated in vivo during infusion of lipid emulsion to premature infants.

\section{MATERIALS AND METHODS}

Patients. Eight premature infants were studied at the Children's Hospital, University of Helsinki. The mean gestational age was $30.0 \pm 2.5 \mathrm{wk}$ (range 27.6-35.6 wk) and birth weight $1150 \pm 375 \mathrm{~g}$ (range $715-1850 \mathrm{~g}$ ). Seven of them initially required intubation and mechanical ventilation due to respiratory distress syndrome. One infant, also requiring mechanical ventilation, had early neonatal septicemia due to Haemophilus influenzae, but leukocyte count and $\mathrm{C}$-reactive protein had become normal before the study. The other patients did not have infections during the first 10 postnatal days. More than $2 \mathrm{~d}$ before the study, two patients received indomethacin for treatment of patent ductus arteriosus. None of the patients had malformations or surgery. The study protocol was approved by the Ethics Committee of the Children's Hospital, University of Helsinki, and informed consent was obtained from the parents.

Parenteral nutrition with glucose, amino acids, and lipid was started on clinical indications at the age of $5.0 \pm 1.2 \mathrm{~d}$ (range 4$7 \mathrm{~d}$ ). Vitamins (A, $350 \mathrm{IU}$; D, $60 \mathrm{IU}$; E, $0.7 \mathrm{IU} ; \mathrm{C}, 15 \mathrm{mg}$; and $\mathrm{K}, 0.02 \mathrm{mg}$ daily) were given parenterally together with the lipid. IL (KabiVitrum, Stockholm, Sweden), a soybean oil mixture, was used in parenteral nutrition. The patients received $10 \%$ IL at constant rates of 1.3 to $2.5 \mathrm{mg} / \mathrm{kg} / \mathrm{min}$; mean $1.6 \pm 0.5 \mathrm{mg} /$ $\mathrm{kg} / \mathrm{min}$. Measurements of expired pentane were performed on every patient one or two times before the onset of the first lipid infusion. They were repeated at the end, and again at 2 and $5 \mathrm{~h}$ after cessation of the infusion. To five of the six patients, this protocol was repeated on the next day. In three patients, the measurements were performed $0,10,20,50$, and $160 \mathrm{~min}$ after lipid infusion at a rate of $1.4 \pm 0.2 \mathrm{mg} / \mathrm{kg} / \mathrm{min}$. On two patients, the procedure was repeated on the following day.

During collection of expired breath, the patients were ventilated manually with a hydrocarbon-free mixture of air and 
oxygen via a nonrebreathing valve for $5 \mathrm{~min}$, after which expired breath was collected for 2 min for analysis.

One of the patients remained on ventilator until death at the age of $48 \mathrm{~d}$ due to uremia, bronchopulmonary dysplasia, and septicemia. Another patient required mechanical ventilation up to the age of $3 \mathrm{wk}$. The others did not require ventilation beyond $10 \mathrm{~d}$ of age. Two developed grade I intraventricular hemorrhage, but none had bronchopulmonary dysplasia at the age of $4 \mathrm{wk}$.

Generation of pentane and MDA from IL in vitro. Twenty $\mu \mathrm{L}$ of $10 \%$ IL were incubated in $0.5 \mathrm{~mL}$ of $10 \mathrm{mM}$ Tris- $\mathrm{Cl}, \mathrm{pH} 7.4$, in airtight ampoules $(5 \mathrm{~mL})$. The head space was replaced with hydrocarbon-free air. Lipid peroxidation was propagated by 10 $\mathrm{mM} \mathrm{H} \mathrm{H}_{2} \mathrm{O}_{2}$ and $200 \mu \mathrm{M} \mathrm{FeCl} \mathrm{F}_{2}$ for $2 \mathrm{~h}$ at $37^{\circ} \mathrm{C}$. SOD and CAT (SOD from bovine erythrocytes and CAT from bovine liver, Sigma Chemical Co., St. Louis, MO), $100 \mathrm{U} / \mathrm{mL}$ each, or 10 $\mathrm{mM}$ vitamin $\mathrm{C}$ were added where indicated.

The amount of pentane present in commercial preparations of lipid emulsion was measured in a $20-\mu \mathrm{L}$ aliquot of $10 \% \mathrm{IL}$. The samples were transferred to the ampoules filled with hydro-

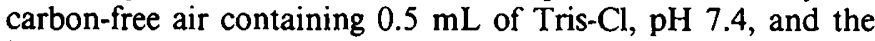
internal standard. Pentane and ethane in the lipid preparation were trapped during $2 \mathrm{~min}$ and quantitated as described below. MDA was measured as described (15).

In vitro hemolysis. Fresh leukocyte-free human erythrocytes

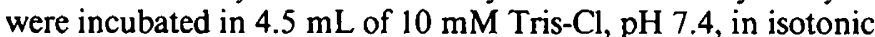
saline (final hematocrit 0.25 ), at $37^{\circ} \mathrm{C}$ under continuous shaking $(100 / \mathrm{min})$. Where indicated, a final concentration of 4.4 or $0.44 \%$ (vol/vol) IL with or without $200 \mu \mathrm{M} \mathrm{Fe}{ }^{2+}$ was present. For determination of hemolysis, aliquots of $0.5 \mathrm{~mL}$ were taken at $0,4,8,12,16$, and $22 \mathrm{~h}$. The sample was diluted in $4.5 \mathrm{~mL}$ of isotonic saline and centrifuged at $600 \times g$ for $10 \mathrm{~min}$. To sediment the lipids, $600 \mu \mathrm{L}$ of the supernatant was vigorously shaken with $400 \mu \mathrm{L}$ Lipoclean (Behringwerke AG, Marburg, West Germany) and centrifuged for $5 \mathrm{~min}$ at $1000 \times g$. The lipid-free supernatant was separated and used for measurement of $\mathrm{Hb}(16)$. At the end of the experiment $(22 \mathrm{~h})$, a $0.5-\mathrm{mL}$ aliquot was taken for the determination of total hemolysis by adding 4.5 $\mathrm{mL}$ distilled water. After centrifugation, the supernatant was used for determination of $\mathrm{Hb}$ as above.

The effect of free radical scavengers on hemolysis was studied by adding $1 \mathrm{mM}$ vitamin $\mathrm{C}$ or $0.25 \mathrm{mM}$ vitamin $\mathrm{E}$ ( $\alpha$-tocopherol, Sigma Chemical Co.) to a mixture containing erythrocytes and $0.44 \%$ IL. After incubation for $22 \mathrm{~h}$, the hemolysis was quantitated as above.

Analysis of pentane and ethane. For the quantitation of pentane and ethane, 2-pentene was used as the internal standard. In in vitro experiments, $25 \mathrm{pmol}$ of 2-pentene was added to the reaction vial before collection of the gas phase. To the samples of expired breath, $50 \mathrm{pmol}$ of 2-pentene were added, after which $300 \mathrm{~mL}$ of the specimen were taken for analysis. Ethane and pentane were measured by gas-chromatography with capillary column as previously described (17).

Statistical analysis. The data are presented as mean \pm SD. Statistical significance was analyzed using the two-tailed $t$ test.

\section{RESULTS}

Commercial $10 \%$ IL contained $2.10 \pm 0.72 \mu \mathrm{M}(n=5$, range 1.2 to $3.0 \mu \mathrm{M})$ pentane, suggesting lipid peroxidation during storage. Extensive purging of IL with helium for $10 \mathrm{~min}$ completely removed the dissolved pentane. After incubation of helium-washed $10 \%$ IL at $37^{\circ} \mathrm{C}$ for $2 \mathrm{~h}$ in air, the concentration of pentane was $0.39 \pm 0.33 \mu \mathrm{M}$. Addition of $10 \mathrm{mM} \mathrm{H}_{2} \mathrm{O}_{2}$ and 200 $\mu \mathrm{M} \mathrm{FeCl}$ increased this to $0.99 \pm 0.19 \mu \mathrm{M}$. SOD and CAT inhibited the induction by $89.1 \%$, and vitamin $C$ inhibited induction by $69.7 \%$. The amount of ethane in the $20-\mu \mathrm{L}$ aliquots was under the detection limit $(1 \mathrm{pmol})$. In the experiment with $10 \%$ IL alone, $0.010 \pm 0.001 \mu \mathrm{M}$ MDA was detected as compared with $0.380 \pm 0.025 \mu \mathrm{M}$ in the presence of $\mathrm{H}_{2} \mathrm{O}_{2}$ and ferrous ion.
Addition of SOD + CAT or vitamin C to the incubation mixture decreased MDA by 96 and $95 \%$, respectively (Table 1).

In erythrocytes incubated for $22 \mathrm{~h}$ with ferrous iron, hemolysis was $11.0 \pm 3.2 \%$ (Fig. 1). Addition of IL ( $4.4 \%$ final concentration) with or without ferrous iron caused significant hemolysis beginning at $12 \mathrm{~h}$. After $16 \mathrm{~h}$, there was $65.2 \pm 13.3 \%$ hemolysis in the presence and $23.0 \pm 5.2 \%$ in the absence of iron, and at $22 \mathrm{~h}$ hemolysis was complete in both (Fig. 1). Hemolysis in the presence $0.44 \%$ IL and ferrous iron for $22 \mathrm{~h}$ was $66.5 \pm 3.4 \%$. Addition of vitamin $\mathrm{E}$ or $\mathrm{C}$ reduced this to $16.4 \pm 8.1 \%(p<$ $0.0001)$ and $38.9 \pm 7.1 \%(p<0.0001)$, respectively (Fig. 2).

In the patients, the basal amount of pentane in expired breath was $12.2 \pm 5.5 \mathrm{pmol} / \mathrm{kg} / \mathrm{min}$. At the end of the IL infusion, this

Table 1. Production of pentane and MDA in IL after induced lipid peroxidation*

\begin{tabular}{lll}
\hline & Pentane $(\mu \mathrm{M})$ & \multicolumn{1}{c}{ MDA $(\mathrm{mM})$} \\
\hline Control & $0.39 \pm 0.33$ & $0.010 \pm 0.001$ \\
$\mathrm{H}_{2} \mathrm{O}_{2}$ & $0.99 \pm 0.19 \dagger$ & $0.380 \pm 0.025 \dagger$ \\
$\mathrm{H}_{2} \mathrm{O}_{2}+$ SOD + CAT & $0.46 \pm 0.18 \ddagger$ & $0.023 \pm 0.007 \ddagger$ \\
$\mathrm{H}_{2} \mathrm{O}_{2}+$ vitamin C & $0.57 \pm 0.15 \ddagger$ & $0.029 \pm 0.003 \ddagger$ \\
\hline
\end{tabular}

* Twenty $\mu \mathrm{L}$ of IL were incubated with $200 \mu \mathrm{M} \mathrm{FeCl}_{2}$ and $10 \mathrm{mM}$ $\mathrm{H}_{2} \mathrm{O}_{2}$. In the control experiment, $\mathrm{H}_{2} \mathrm{O}_{2}$ was omitted. SOD and CAT were added at $100 \mathrm{U} / \mathrm{mL}$ each. The final concentration of vitamin $\mathrm{C}$ was 10 $\mathrm{mM}$. Results are presented as means $\pm \mathrm{SD}$ of six parallel experiments.

$\dagger$ Different from control at $p<0.0001$.

$\ddagger$ Different from $\mathrm{H}_{2} \mathrm{O}_{2}$ at $p<0.0001$.

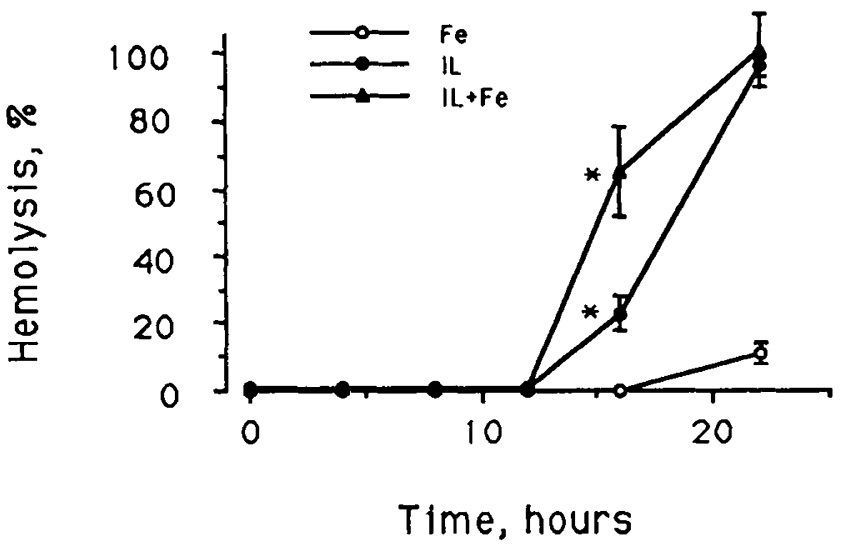

Fig. 1. The effect of IL on human erythrocytes in vitro. Erythrocytes were incubated in the presence of $200 \mu \mathrm{M} \mathrm{FeCl}_{2}(\mathrm{Fe})$, or in $4.4 \% \mathrm{IL}$ without $(I L)$ or with $200 \mu \mathrm{M} \mathrm{FeCl}_{2}(I L+F e)$. In the control experiment without $\mathrm{Fe}$ or IL, hemolysis was less than $1 \%$. Results are presented as means \pm SD of six parallel experiments. ${ }^{*}$ Different at $p<0.001$

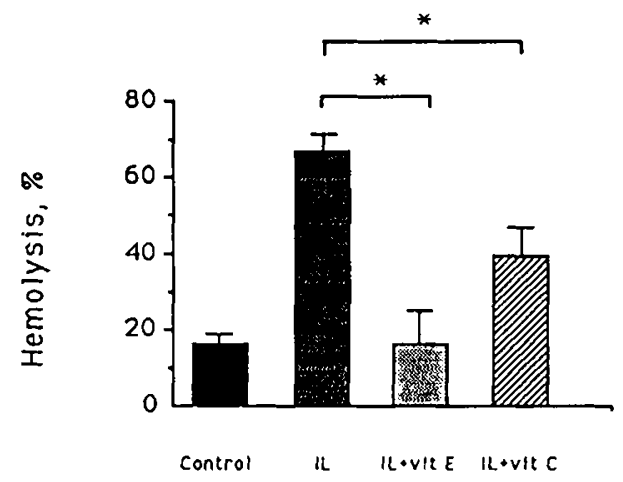

Fig. 2. The effect of IL and antioxidants on human erythrocytes. Erythrocytes were incubated in $0.44 \% \mathrm{lL}$ or buffer alone, both containing $200 \mu \mathrm{M} \mathrm{FeCl}_{2}$. The final concentration of vitamin $\mathrm{C}$ was $1 \mathrm{mM}$, and that of vitamin E $250 \mu \mathrm{M}$. Results are presented as means \pm SD of six parallel experiments. ${ }^{*}$ Different at $p<0.0001$. 


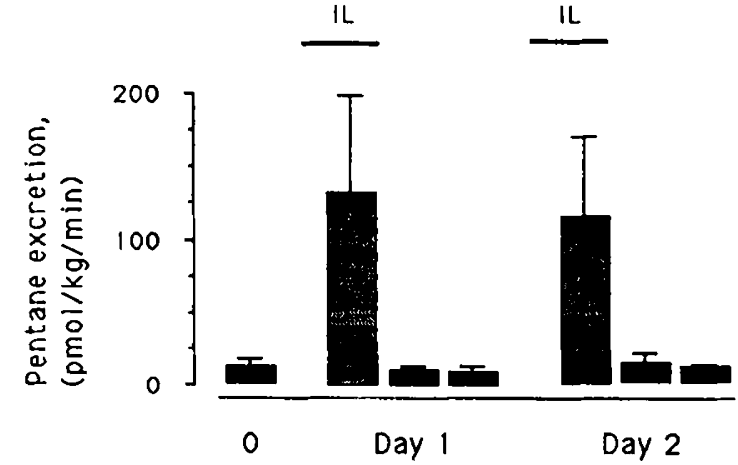

Fig. 3. Expired pentane in premature infants receiving IL. Ten percent IL was infused at a rate of 1.3 to $2.5 \mathrm{mg} / \mathrm{kg} / \mathrm{min}$ for $6 \mathrm{~h}$ on 2 subsequent days to six infants; gestational age $31.1 \pm 3.3 \mathrm{wk}$; postnatal age $5.0 \pm 1.2 \mathrm{~d}$ at the beginning of IL. Expired pentane in breath was measured before IL, at the end of the infusion, and 2 and $5 \mathrm{~h}$ after cessation of the infusion. Results are presented as means \pm SD of six measurements.

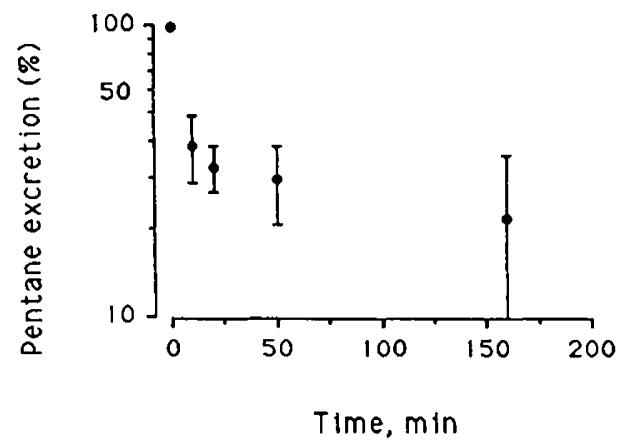

Fig. 4. Elimination of pentane after the lipid infusion. Ten percent IL was infused to three premature infants (gestational age $28.9 \pm 1.2 \mathrm{wk}$, birth weight $853 \pm 136 \mathrm{~g}$ ) at a rate of $1.4 \pm 0.2 \mathrm{mg} / \mathrm{kg} / \mathrm{min}$. Expired pentane immediately before cessation of the infusion (range 76.3-127 $\mathrm{pmol} / \mathrm{kg} / \mathrm{min}$ ) was used as a reference and assigned the value of $100 \%$. The values are presented as mean \pm SD on a logarithmic scale.

increased to $117 \pm 61.5 \mathrm{pmol} / \mathrm{kg} / \mathrm{min}(p<0.001, n=13)$. Two $\mathrm{h}$ after cessation of lipid infusion, pentane had declined to $9.5 \pm$ $2.8 \mathrm{pmol} / \mathrm{kg} / \mathrm{min}(n=13)$, and $3 \mathrm{~h}$ later it remained low at 12.4 $\pm 5.9 \mathrm{pmol} / \mathrm{kg} / \mathrm{min}(n=7)$ (Fig. 3). At the end of the IL infusion, ethane varied widely and was exhaled at a rate of $21.6 \pm 25.3$ $\mathrm{pmol} / \mathrm{kg} / \mathrm{min}$ compared with the value $5.3 \pm 7.6 \mathrm{pmol} / \mathrm{kg} / \mathrm{min}$ measured before the infusion (NS).

In three patients, the decline of pentane in breath was followed at closer intervals after discontinuing the lipid infusion. Initially, a rapid phase of elimination with a $t_{1 / 2}$ of 12 min or less was evident. Thereafter, pentane in breath decreased more gradually toward the basal level (Fig. 4).

\section{DISCUSSION}

In our study, we have demonstrated that a lipid emulsion used in parenteral nutrition undergoes peroxidation that causes freeradical-mediated damage to human cells in vitro. The generation of free radicals in the lipid emulsion was documented by several findings. Incubation of IL with hydrogen peroxide and ferrous iron increased the generation of pentane. This alkane is produced in free-radical-induced peroxidation of linoleic acid, the main constituent of IL $(4,13,17)$. The production of MDA also increased significantly. The generation of both these products of lipid peroxidation was inhibited by antioxidants. Furthermore, the experimental system demonstrated lipid emulsion-induced hemolysis in which erythrocytes were protected by the naturally occurring radical scavengers, vitamin $\mathrm{E}$ and vitamin $\mathrm{C}$.
Recently, the significance of lipid peroxidation has been under discussion (18). Although, to a degree, peroxidation is part of normal metabolism, profound lipid peroxidation is associated with definite tissue injury in vivo $(18,19)$. As shown here and in other studies, human cell membranes are susceptible to damage mediated by free radicals $(20,21)$. Lipid emulsions for parenteral nutrition are also prone to lipid peroxidation upon storage, as indicated by the presence of pentane in IL. The amount of vitamin $\mathrm{E}$ in $\mathrm{IL}(0.02 \mathrm{IU} / \mathrm{mL}=36 \mu \mathrm{M})$ is not sufficient to inhibit the peroxidation.

The infusion of IL to premature babies, at rates used in clinical practice, caused a nearly 10 -fold increase in expired pentane. This is in accordance with the results of Wispe et al. (22). A fraction of the increase is derived from preformed pentane infused to the patient in the lipid emulsion. However, the amount of pentane measured in expired breath during the 2-min collection exceeded the amount of pentane given to the patient in the infusate by 3 - to 4 -fold. Therefore, it is evident that pentane is generated in the process of lipid peroxidation in vivo. The maximum amount of pentane expired during infusion of IL was close to that observed by Wispe et al. (22). Smaller amounts of pentane have been found in adult patients receiving parenteral lipid emulsion. However, those results were obtained after discontinuing the infusion (23). We could not show any clear correlation between ethane production and IL infusion. In general, the basal ethane and pentane excretion rates were low in our patients, reflecting the stable clinical condition of the patients (9).

The elimination rate of pentane in breath after discontinuation of IL was nonexponential. The initial rapid phase may mainly be due to dissolved pentane formed during storage of IL. However, further elimination of pentane produced in vivo was more gradual (Fig. 4). In our study, in contrast to a previous report (22), pentane returned to the basal level by $5 \mathrm{~h}$ after cessation of IL. Wispe et al. (22) examined pentane and ethane production after continuous infusion of safflower oil emulsion to one term infant not receiving supplementary oxygen. Initially, pentane decreased with an apparent $\mathrm{t}_{1 / 2}$ of $2 \mathrm{~h}$, followed by a more gradual decline $(43-59 \%$ in $24 \mathrm{~h})$. The difference in the elimination rate of pentane after the lipid emulsion may be explained either by the differences in the quality and quantity of lipid emulsion or by differences in patient characteristics.

In this investigation, only one of the eight preterm infants died and none of the others developed severe sequelae (bronchopulmonary dysplasia, retinopathy of prematurity, cerebral palsy). However, in a study of sick premature infants, the use of lipid emulsions was associated with increased incidence of complications such as bronchopulmonary dysplasia and retinopathy of prematurity (7). We have previously shown that, in very-lowbirth-weight newborns who later died or developed chronic disease, lipid peroxidation was significantly higher during the first days of life than it was in patients of comparable gestational age with a favorable outcome (9). As shown here, lipid emulsions are prone to peroxidation and generation of free radicals. Therefore, it is possible that in susceptible patients the lipid peroxidation products generated by lipid emulsions exceed the capacity of the organism to inactivate free radicals (10). The excess of free radicals may in turn be a factor that contributes to the complications encountered in premature infants receiving IL. It remains to be studied whether the generation of free radicals and complications in patients receiving parenteral nutrition can be decreased by antioxidant therapy.

Acknowledgment. The authors thank Dr. Maija Pohjavuori, M.D., and the personnel of the neonatal intensive care unit of Children's Hospital, Helsinki, for their kind cooperation. 


\section{REFERENCES}

1. Pereira G, Fox W, Stanley C, Barker L, Schwartz J 1980 Decreased oxygenation and hyperlipemia during intravenous infusions in premature infants. Pediatrics 66:26-30

2. McKeen C, Brigham K, Bowers R, Harris T 1978 Pulmonary vascular effects of fat emulsion infusion in unanesthetized sheep. J Clin Invest 61:12911297

3. Sundström G, Zauner C, Arborelius M 1974 Decrease in pulmonary diffusion capacity during lipid infusion in healthy men. J Appl Physiol 34:816-820

4. Levene MI, Wigglesworth JS, Desai R 1980 Pulmonary fat accumulation after intralipid infusion in the preterm infant. Lancet 2:815-819

5. Greene H, Haqlett D, Demaree R 1976 Relationship between Vitrum-induced hyperlipemia and pulmonary function. Am J Clin Nutr 29:127-135

6. Shulman RJ, Langston C, Schanler RJ 1987 Pulmonary lipid deposition after administration of intravenous fat to infants. Pediatrics 79:99-102

7. Hammerman C, Aramburo MJ 1988 Decreased lipid intake reduces morbidity in sick premature neonates. J Pediatr 113:1083-1088

8. Freeman BA, Crapo JD 1982 Free radicals in tissue injury. Lab Invest 47:412426

9. Pitkänen OM, Hallman M, Andersson SM 1990 Correlation of free oxygenradical induced lipid peroxidation with outcome in very low birth weight infants. J Pediatr 116:760-764

10. Frank L. Sosenko IRS 1987 Development of lung antioxidant enzyme system in late gestation: possible implications for the prematurely born infant. J Pediatr 110:9-14

11. Merritt TA, Cochrane CG, Holcomb K, Bohl B, Hallman M, Strayer D,
Edwards III DK 1983 Elastase and $\alpha_{1}$-proteinase inhibitor activity in tracheal aspirates during respiratory distress syndrome. J Clin Invest 72:656-666

12. McCord JM 1985 Oxygen-derived free radicals in postischemic tissue injury. N Engl J Med 312:159-163

13. Gardner HW 1989 Oxygen radical chemistry of polyunsaturated fatty acids. Free Radic Biol Med 7:65-86

14. Frankel EN 1980 Lipid oxidation. Prog Lipid Res 19:1-22

15. Hatherill RJ, Till GO, Bruner LH, Ward PA 1986 Thermal injury, intravascular hemolysis, and toxic oxygen products. J Clin Invest 78:629-636

16. Harboe M 1959 A method for determination of hemoglobin in plasma by near-ultraviolet spectrophotometry. Scand J Clin Lab Invest 11:66-70

17. Pitkänen OM, Hallman M, Andersson SM 1989 Determination of ethane and pentane in free oxygen radical-induced lipid peroxidation. Lipids 24:157159

18. Dormandy TL 1988 In praise of lipid peroxidation. Lancet $2: 1126-1128$

19. Winyard PG, Blake DR, Chirico S, Gutteridge JMC, Lunec J 1987 Mechanism of exacerbation of rheumatoid synovitis by total-dose iron-dextran infusion: in vivo demonstration of iron-promoted oxidant stress. Lancet 1:69-72

20. Niki E, Komuro E, Takahashi M, Urano S, Ito E, Terao K 1988 Oxidative hemolysis of erythrocytes and its inhibition by free radicals scavengers. J Biol Chem 263:19809-19814

21. Davies KJA, Goldberg AL 1987 Oxygen radicals stimulate intracellular proteolysis and lipid peroxidation by independent mechanisms in erythrocytes. J Biol Chem 262:8220-8226

22. Wispe JR, Bell EF, Roberts RJ 1985 Assessment of lipid peroxidation in newborn infants and rabbits by measurements of expired ethane and pentane: newborn infants and rabbits by measurements of expired ethane

23. Lemoyne $M$, Van Gossum A, Kurian R, Jeejeebhoy KN 1988 Plasma vitamin $\mathrm{E}$ and selenium and breath pentane in home parenteral nutrition patients. Am J Clin Nutr 48:1310-1315 